\title{
OS SENTIDOS DA MODERNIZAÇÃO
}

\author{
MODERNIZATION OF THE SENSES
}

\section{LOS SENTIDOS DE LA MODERNIZACIÓN}

\author{
Denis Castilho - Universidade Federal de Goiás - Goiânia - Goiás - Brasil \\ deniscastilho@hotmail.com
}

\section{Resumo}

A modernização se apresenta como um projeto da modernidade feita a partir de uma ideologia desenvolvimentista, do progresso e da racionalidade. Como expansão do modo de produção capitalista pelos lugares, ela se estabelece a partir de dois modelos principais: um político e ideológico; e outro de base técnica e infraestrutural. Nesse sentido, os atores hegemônicos, renovam constantemente os instrumentos e as relações de produção assim como os discursos (do que a ciência não se isenta) que justificam e até "naturalizam" a modernização como um processo necessário ao "progresso social". A forte difusão desse conceito no âmbito político é proveniente da forma autoritária como ele foi imposto em países como o Brasil e da maneira como o discurso se reproduz a partir de uma determinada classe. Este artigo debate essas questões mediante uma revisão de autores que trabalham o conceito e de uma crítica à forma como alguns abordam o tema por meio de uma concepção reducionista de espaço e de interpretações dualistas. Levanta também algumas questões acerca dos estudos que analisam a modernização com enfoque na modernidade e suas tendências paradigmáticas sem, contudo, entrar na discussão política, histórica e espacial do fenômeno.

Palavras-chave: modernização, ideologia, espaço, crítica às dualidades.

\section{Abstract}

The modernization is presented as a project of modernity made from a developmentalist ideology of the progress and rationality. As an expansion of the capitalist way through places, it is established from two main models: a political and ideological, and other technical and infrastructural bases. The hegemonic aspects in this sense constantly renew the relations among production and instruments as well as speeches (which science is not free) justify and even "naturalize " the modernization as a necessary requisite for "social progress". The strong diffusion of the empty concept of a political debate comes from the authoritarian way in which was imposed in countries like Brazil and the way the speech is reproduced from a particular class. This article proposes to discuss these issues through a review of authors who study the concept and from a critique of the way some talk about the subject through a reductionist conception of space and dualistic interpretations.It also raises some questions about the studies that analyze the modernization with a focus on modernity and its paradigmatic trends but without going into the political, historical and spatial phenomenon.

Key words: modernization, ideology, space, criticism to dualities.

\section{Resumen}

La modernización se presenta como un proyecto de la modernidad hecha a partir de una ideología del desarrollo, del progreso y de la racionalidad. Como expansión del modo de producción capitalista por los lugares, la modernización se establece a partir de dos modelos principales: un político e ideológico, y otro de base técnica e infraestructural. Los actores hegemónicos, en este sentido, actualizan, constantemente, los instrumentos y las relaciones de producción así como los discursos (de los cuales la ciencia no si exenta) que legitiman la modernización como un proceso necesario para el "progreso social". La fuerte difusión del concepto vacío de un debate político viene de la forma autoritaria como él fue impuesto en países como el Brasil y de la manera como el discurso se reproduce por una clase en particular. Este artículo propone 
discutir esas cuestiones a través de una revisión de los actores que estudian el concepto de modernización y de una crítica de como algunos analizan el tema a través de una concepción reduccionista del espacio y de interpretaciones dualistas. También algunas preguntas son hechas sobre los estudios que analizan la modernización con un enfoque en la modernidad y sus tendencias paradigmáticas, pero sin entrar en la discusión política, histórica y espacial del fenómeno.

Palabras clave: modernización, ideología, espacio, crítica a las dualidades.

\section{Introdução}

Palavras como globalização, mundialização, modernidade e modernização ultrapassaram as fronteiras das áreas do conhecimento e passaram a compor o vocabulário dos debates acadêmicos e políticos, especialmente nos últimos anos. $\mathrm{O}$ uso desses conceitos, especialmente o de modernidade e modernização, se difundiu na história e na literatura a partir das revoluções britânica (industrial) e francesa, ambas no século XVIII. Se a primeira forneceu o modelo econômico para a inovação dos meios de produção, a revolução francesa, especialmente com o Iluminismo, forneceu o modelo político e ideológico da modernização.

Nas últimas décadas do século XX e início do século XXI, a modernização tem sido assunto em um crescente número de publicações ${ }^{1}$ tanto no terreno do conhecimento científico como no universo político e nos meios de informação. Diante do volume de publicações e até mesmo de certo modismo, questionamos se tais publicações têm tido uma atenção conceitual com o tema. É provável que a difusão em massa do conceito represente uma "armadilha", sobretudo para os despercebidos e para aqueles que aceitam a modernização como algo natural e necessário ao processo econômico. As ciências humanas, nesse sentido, se deparam com o desafio de compreender a complexidade desse processo ao mesmo tempo em que se veem diante da naturalização do conceito sem uma crítica à forma como é produzido.

Diante desse contexto, em que a globalização e/ou a modernização geralmente protagonizam o tom das discussões, a Geografia, por estabelecer o debate pelo viés espacial, passa a representar uma das condições básicas para o entendimento deste fenômeno. Mas como esta ciência tem participado do debate sobre a "modernização" e como autores de outras áreas do conhecimento têm dado atenção ao espaço nas análises deste fenômeno?

Essas questões orientaram as reflexões desse estudo. Assim, o nosso objetivo é analisar o conceito de modernização e a forma como tem sido 
abordado sem uma preocupação teórica e política. Também desenvolvemos uma crítica à forma como alguns autores abordam o tema a partir de uma concepção reducionista de espaço e de interpretações por meio dos pares opostos e separados - tradicional/moderno, antigo/novo, modernidade/pós-modernidade etc., como se a complexa dinâmica da modernização pudesse ser enquadrada em interpretações dualistas.

\section{0 conceito de modernização e o debate sobre o espaço}

Segundo o dicionário Houaiss da língua portuguesa, a palavra modernização se forma a partir do verbo modernizar com o sufixo ção (ação). "É o ato ou efeito de modernizar [...] é tornar(-se) moderno, acompanhando a evolução e as tendências do mundo atual" (Houaiss e Villar, 2001, p. 1941). Ainda, de acordo com este dicionário, moderno é um período histórico que se iniciou com o fim da Idade Média. De acordo com Gray (2004), a palavra moderno apareceu na língua inglesa no final do século XVI. "De início significava pouco mais que ser do tempo presente, mas lentamente veio a trazer um senso de novidade. 'Modern' significava alguma coisa que jamais existiria antes" (Gray, 2004, p. 121).

Do ponto de vista da expansão territorial, a modernização tem dois sentidos principais: um que envolve a infraestrutura econômica, a base técnica e os meios de produção e outro que envolve os aspectos políticos e ideológicos. De acordo com Hobsbawm (1996), se a Revolução Industrial britânica forneceu o modelo para as fábricas, rodovias, cidades, infraestrutura, emprego das técnicas etc., a Revolução Francesa forneceu o modelo político e ideológico do processo de modernização. Para Giddens (1984, p. 111), "a teoria da modernização está associada diretamente à teoria da sociedade industrial”. O conceito de modernização, nesse sentido, é abrangente, já que está relacionado a um conjunto de transformações que se processam nos meios de produção, mas também na estrutura econômica, política e cultural de um território. Para se expandir espacialmente, a modernização entra no jogo dos debates teóricos e geralmente é justificada ideologicamente nas instituições acadêmicas, no universo político e nos meios de informações. Assim, modernização não se refere, única e exclusivamente, às transformações que se processam nos meios de produção e nas bases técnicas, pois envolve um conjunto de valores que, advindos de uma determinada classe social, se apresenta com forte caráter ideológico. 
Autores como Eisenstadt (1968), Black (1971), Germani (1974), Habermas (2002) e Schwartzman (2004) apresentam um debate sobre a dinâmica da modernização. Este último apregoa que o termo "existe no mundo das ideias como valores e afirmações morais sobre a vida humana [...] e como interpretação de um amplo processo de mudança social" (2004, p.16). Schwartzman (2004, p. 18) afirma ainda que a expansão da modernidade era descrita a partir de termos como progresso e evolução. "Mais tarde, economistas começaram a falar de 'desenvolvimento econômico'. Muito mais recentemente, cientistas sociais adotaram o termo modernização". ${ }^{2}$

Trata-se da expansão da própria modernidade do ponto de vista territorial. A sua expressão pode ser identificada nas ruas, nas formas urbanas, nos sistemas de transporte, nos contrastes das cidades, nos diferentes lugares, na velocidade, na circulação de mercadorias etc. Marx e Engels (1998), no Manifesto comunista, observam como a burguesia vai tomando conta dos lugares a partir de uma contínua expansão do capital em nível mundial por meio do desenvolvimento tecnológico, da mercantilizarão etc. Para os autores, essa referida classe cria um mundo à sua imagem em um processo que promove a captura dos lugares e que pode ser. chamado de modernização.

A burguesia precisa instalar-se em todos os lugares, acomodar-se em todos os lugares, estabelecer conexões em todos os lugares. [...] No lugar da antiga reclusão e autossuficiência local e nacional, temos conexões em todas as direções. [...] A burguesia, pelo aperfeiçoamento rápido de todos os instrumentos de produção, pelos meios de comunicação imensamente facilitados, arrasta todas as nações, até a mais bárbara, para a civilização.[...] Resumindo, cria um mundo à sua imagem. (Marx e Engels, 1998, p. 14-15)

Conforme os autores "a burguesia não pode existir sem revolucionar, constantemente, os instrumentos de produção e, desse modo, as relações de produção e, com elas, todas as relações da sociedade" (Marx e Engels, 1998, p. 13). A expansão desse processo pelos lugares é o que chamamos de modernização. O termo, nesse sentido, constitui uma representação teórica do processo de imposição das relações sociais de produção pelas classes hegemônicas. Modernização é a expansão territorial, portanto, do próprio modo de produção capitalista.

Viana (2009) afirma que modernização é o processo de avanço da sociedade moderna sobre outras sociedades ou sua própria atualização. 
Assim, modernização é um projeto da modernidade feito a partir de uma ideologia desenvolvimentista, do progresso e da racionalidade. Black (1971) afirma que o conceito de modernização refere-se a uma dinâmica adotada pelo processo de inovação mediante a proliferação explosiva de conhecimentos nos últimos séculos. Este processo, segundo o autor, é extremamente criativo, mas em contrapartida, também é extremamente destrutivo, promovendo sofrimento e degradação humana, em seu processo de inovação e renovação. Kurz (1992) também analisa a modernização como um processo contraditório, o qual desencadeará colapsos pelo mundo. O autor afirma que a quebra das economias socialistas explicitaria, na realidade, os impasses do sistema global moderno. Com um tom desmascarador o autor afirma que o mundo único (global) não poderá conter as revoltas de fome e desespero de várias partes do mundo, reforçando que o desastre da modernização atingirá seu causador e também os atores que o criaram.

Entre outros autores que apontam as cosequências do processo de modernização, podemos mencionar os trabalhos de Furtado (1974), Giddens (1991), Eisenstadt (1969), Reis (1988), Andrade (1994), Braudel (1996), Ortiz (2003), Berman (1982), Ianni (2000) e Oliveira (2003). No contexto das análises sobre a expansão do modo de produção capitalista, a pobreza, a concentração de renda e as desigualdades sociais são apontadas como as principais consequências do processo de modernização. Aliás, isso contradiz um dos principais ideários modernos do pensamento iluminista: o de que o progresso da sociedade seria fruto do progresso da ciência. A modernização, nesse sentido, seria a expansão do próprio desenvolvimento humano pleno. No entanto, a história tratou de evidenciar o equívoco das previsões iluministas e a crise dos sistemas modernos de produção estaria dando lugar ao que alguns autores chamam de pós-modernidade e pós-modernismo. ${ }^{3}$

Uma característica peculiar das sociedades modernizadas, como defende Eisenstadt (1968), é o seu caráter diferencial. Se por um lado a modernização intenta promover certa homogeneização dos lugares, ela acaba por diferenciá-los ainda mais. Giddens (1991) considera a modernidade não apenas pelo seu impacto global, mas também pelo seu caráter dinâmico capaz de impor mudanças radicais sobre os valores tradicionais. Este autor também vê, a partir da modernização, uma separação do tempo e do espaço assim como o que ele chama de "desencaixe das relações sociais”. Nas sociedades tradicionais (pré-modernas), cada espaço tinha seu 
tempo específico. Com a imposição das lógicas modernas e com a mecanização do tempo pelo relógio (idealização de um horário mundial), houve o rompimento ou desencaixe (uma separação das relações sociais, antes ligadas a seus contextos locais). Ou seja, se as comunidades tradicionais têm fortes ligações com o local (sendo encaixadas), as sociedades modernas são desencaixadas de seus próprios locais por atuarem segundo forças de outras escalas. As relações sociais seriam reencaixadas segundo a nova dinâmica mundializada. O autor dissocia então o tempo do espaço ao afirmar que os locais passariam a ser penetrados e moldados por influências sociais bem distantes deles. A modernidade estaria, assim, engendrando "espaços vazios".

Diante desse "novo" contexto de modernização, Virilio (1993) assegura que o tempo diminuiu o espaço. Bauman (1999) também traz uma concepção de espaço como se este fosse sinônimo de distância. Estaria havendo uma compressão espaço-temporal, como tem atestado Harvey (1993), pela forma como as informações circulam na atualidade. No entanto, o conceito de espaço levantado pelos autores não estaria limitado à ideia de extensão, distância, intervalo entre dois ou mais pontos? Logicamente, desse ponto de vista o espaço estaria deixando de ser um grande obstáculo. De um modo geral, para esses autores, a modernização "comprimiu o espaço", engendrou "espaços vazios" e até mesmo "dissociou o espaço do tempo", afirmações que merecem uma análise crítica. Até porque a existência dos fenômenos se estabelece por uma ordem espacial, sendo impossível a dissociação entre espaço e tempo, já que a própria existência pressupõe uma dimensão espaço-temporal (Gomes, 2009). O espaço também não foi suplantado nem diminuído. O meio técnico-científico-informacional (Santos, 1994) é que proporcionou maior circulação dos objetos e das ações, fazendo emergir o tempo veloz. No caso da modernização, como afirmou Santos (1988), é nos lugares que ela se concretiza. Sem acontecer nos lugares, a modernização não tem sentido, torna-se uma coisa abstrata. E continua, afirmando:

a multiplicação das ações [...] fazem do espaço um campo de forças multidirecionais e multicomplexas, onde cada lugar é extremamente distinto do outro, mas também claramente ligado a todos os demais por um nexo único, dado pelas forças motrizes do modo de acumulação hegemonicamente universal. [...] O lugar é um ponto do mundo onde se realizam algumas das possibilidades deste último. (Santos, 1988, p. 34-35; grifo nosso) 
Assim, a modernização não se processa sem, de fato, acontecer em algum lugar, o que significa que ela, enquanto processo de expansão das relações sociais de produção capitalistas, precisa promover uma conexão entre os lugares (Marx e Engels, 1998). A grande questão, por conseguinte, é entender a forma como este processo ocorre. A Geografia, como ciência que procura compreender o sentido espacial dos fenômenos, se apresenta como importante área do conhecimento nessa discussão, já que o debate sobre a modernização e sua dimensão espacial tem se apresentado frágil e limitado, mostrando, em algumas interpretações, uma ligação com a concepção física e geométrica do espaço.

De acordo com Ribeiro (2008), os motivos desta interpretação estão ligados à concepção cartesiana-newtoniana de espaço, a qual admite-o como um conjunto de pontos dispostos sob uma superfície lisa e homogênea. $\mathrm{O}$ autor acrescenta ainda que, representado dessa maneira, tal quadro desemboca, inevitavelmente, no discurso de que o tempo suplantou ou diminuiu o espaço. No entanto, o avanço dos instrumentos de produção e/ou dos meios tecnológicos se materializam a partir de uma distribuição espacial evidente. Se o espaço é produzido a partir das relações sociais de produção, como bem atestou Lefebvre (2000), ele não é diminuído ou suplantado, mas sim transformado na medida em que se renovam os instrumentos e as relações de produção.

Como um projeto europeu, a modernização se impôs em países como o Brasil de maneira vertical e autoritária - e continua sendo reproduzida dessa maneira. Por isso, conforme Santos (1979), "as vicissitudes do desenvolvimento 'moderno' dos países com baixo desenvolvimento econômico estão diretamente ligadas às necessidades dos países industriais”. Esta concepção é válida em outras escalas, como no interior dos próprios países, onde algumas regiões, em períodos distintos, se modernizam conforme as necessidades de outras regiões.

Se essa lógica está diretamente relacionada aos interesses e determinações dos atores hegemônicos, ao contrário do que se costuma afirmar, os efeitos da modernização não são restritos a uma determinada região ou lugar. Além de estar em movimento, ela atinge todas e todos, mas de maneira diferente. Isso torna a dinâmica espaço-temporal da modernização "muito complexa para ser objeto de uma precisa localização, ainda que uma época moderna seja facilmente identificada", como adverte Gomes (1996, p. 28). As transformações socioespaciais que ocorrem em 
uma determinada porção do território devem, portanto, ser compreendidas a partir de determinações e conexões diversas, as quais, como afirmava Gramsci (1987), estão relacionadas a uma "amplitude política de caráter territorial" e não, necessariamente, aos problemas concernentes a uma única região ou fragmento de espaço. Deve-se discutir, portanto, o seu impacto seletivo e segregador, com o cuidado de não cair nas teorias dualistas como se a realidade de determinados locais fosse separada da de outros. Como esse último caminho desemboca, inevitavelmente, em uma teoria fragmentada da realidade, é preciso evitá-lo.

\section{Modernização e crítica às dualidades}

É comum analisar a modernização pelas teorias dualistas ou pelos pares opostos e separados. Haja vista a referência modernidade/encaixe e modernidade/desencaixe de Giddens (1991) e as abordagens que enfocam os pares antigo/novo, tradicional/moderno, centro/periferia etc. Essa abordagem dualista também considera, sobretudo, o par modernidade e pós-modernidade. De acordo com Debord (1997), podemos afirmar que no capitalismo o processo de passagem do "antigo" para o "novo", do "inovado" para o "renovado" etc., representa uma alteração apenas do ponto de vista formal e da aparência das coisas. Altera-se a forma (as ruas, as edificações, a moda, o comportamento, a paisagem etc), mas não se altera as relações sociais de produção.

A tentativa de cindir ou de provocar uma cisão no mundo guarda interesses estratégicos. Tais interesses (de reduzir a explicação a pares tidos como opostos e separados - bem/mal, velho/novo, atrasado/moderno) são reproduzidos no sentido de desviar a atenção e de impedir a sociedade de ser o que ela guarda em potência. Nietzsche (2007), em sua obra Além do bem e do mal, condena essa forma de dividir a vida em apenas dois caminhos. Podemos dizer, portanto, que as análises pela dualidade são formas reducionistas de explicar a realidade.

As teorias dualistas são "naturalizadas" nas sociedades capitalistas. Em alguns casos, os críticos tentam olhar para a modernização mostrando o seu caráter "cruel”, “caricato”, “doloroso”, “conservador”, “desigual”, “imperfeito” etc. Mas a crítica é seguida de uma análise por meio dos pares, como se existisse, em uma só escala, dois mundos opostos e separados. Dizer que a pós-modernidade representa uma (re)significação e até mes- 
mo uma (re)valorização das tradições - como se ela fosse algo posterior à modernidade (uma ruptura, oposição ou separação) - também nos coloca no plano ideológico da dualidade. E parece-nos uma redução conceber a modernização como se ela fosse uma parte separada do tradicional. Santos (1979, p. 55), que já defendia a ideia de que a tradição não é, necessariamente, separada da inovação, considera que, nesse processo, "trata-se "de uma aceitação dos elementos de modernização em diferentes graus". Se um dos impactos da modernização é a diferenciação espacial, como exemplo dos lugares segregados e daqueles centralizados; do "circuito superior" e do "circuito inferior" da economia; etc, isso não significa que esses elementos sejam separados. A dispersão da pobreza e os contrastes visíveis nas paisagens das cidades não representam o reverso de um processo econômico ou o atraso de nosso país, mas o tipo de modernização que aqui foi imposto e reproduzido. Isto é, a modernização existe também na periferia. Neste caso, a pergunta que se deve fazer é: como ela se configura nesse lugar? Qualquer ideia de fragmentação proporcionada pela modernização é, portanto, uma ilusão. Isso porque a relação entre diferentes lugares e diferentes temporalidades representa o funcionamento de uma mesma realidade.

A análise, nesse sentido, deve abarcar a unidade dos contrários, em lugar das separações/oposições antagônicas que caracterizam a alienação, como bem observa Mészáros (1979). Assim, a oposição entre atrasado (ou tradicional) e moderno é apenas formal porque, segundo Oliveira (2003, p. 32), "o processo real mostra uma simbiose e uma organicidade, uma unidade dos contrários, em que o chamado "moderno" cresce e se alimenta da existência do "atrasado", se se quer manter a terminologia". Portanto, não é possível chegar à compreensão da complexa realidade do mundo pela separação dos fenômenos, mas considerando-os a partir de uma unidade contraditória, mas não separada. Assim dito, a crítica deve, também, caminhar no sentido de questionar a quem serve o modelo de modernização que se expande pelo Brasil. É preciso falar de processos, mas também nomear seus atores.

Eisenstadt (1968) analisa as condições pelas quais as sociedades em modernização desenvolvem seu quadro institucional. Para ele, as mudanças sociais se processam historicamente nos sistemas sociais, econômicos e políticos a partir da Europa Ocidental e dos Estados Unidos, espalhando-se por outros países europeus e pelos continentes americano, asiáti- 
co e africano. Esse processo teve como consequência a desorganização, a divisão e o surgimento de conflitos entre grupos e movimentos sociais de resistência às mudanças. Essa desordem ocorre no campo econômico (pela industrialização), no campo político (pela centralização e "democratização") e no campo cultural (pelo rompimento dos valores tradicionais) (Eisenstadt, 1968).

Como se observa, as questões da modernização são levantadas como se o seu principal problema fosse somente a sua má distribuição, que desemboca em conflitos e em movimentos de resistência. Mas na verdade sua raiz (ou a origem de sua concepção) já é por si um problema, já que ela é produzida por uma classe voltada aos seus próprios interesses. Qual seria, nesse sentido, o preço de resistir sem transformar? Tanto as resistências como as críticas contra o processo de modernização são e serão conservadores por não se constituírem em verdadeiros embates que destruam as bases "modernas" de consolidação do poder hegemônico. Os movimentos de resistência e a ciência, neste caso, servem, antes de mais nada, para justificar a modernização.

O uso exagerado do conceito (e até mesmo a sua banalização) corresponde e/ou representa a naturalização da modernidade como fenômeno histórico que coloca a modernização como algo necessário ao desenvolvimento social. Isso significa que o conceito alcançou o plano ideológico, garantindo sua aceitação não só no meio social como também no científico.

Nesse contexto, Ribeiro (2002, p. 150) aponta para uma "tendência ao ocultamento analítico do tema da modernização social; intensamente compensada pela ampla referência à modernidade”. A autora ainda comenta que as múltiplas análises realizadas nos anos de 1980 sobre a modernidade, geralmente não foram acompanhadas por análises consistentes da história do Brasil.

Portanto, no contexto acadêmico, os debates sobre a modernização acabam por estocar uma discussão muito próxima do discurso pelo discurso do que, necessariamente, uma leitura crítica de seus processos espaciais. Enquanto isso, a expansão territorial da modernização é naturalizada no meio social, banalizada de maneira ideológica e, sobretudo, aceita como uma necessidade eminente, num processo em que as consequências sociais, como a pobreza e a segregação, apresentam-se como enfermidades inevitáveis, por isto, aceitas sem grandes discussões.

Germani (1974) analisa o desenvolvimento a partir da culminância de um conjunto de políticas e esforços de modernização, a exemplo 
dos programas de desenvolvimento, da racionalização dos valores e da administração pública, da melhoria da produtividade das empresas etc. Como se observa, quando o tema envolve a modernização, muito se fala de transformações nas formas de produção, dos impactos na gestão, da produtividade das empresas, das novas relações campo/cidade, das novas dinâmicas territoriais etc. No entanto, deixar de averiguar o processo de modernização a partir da formação territorial de um Estado desvendando não só o discurso oficial como também o planejamento no âmbito capitalista (já que ambos se constituem como formas de ações dos atores hegemônicos) significa desviar a atenção teórica e a ação política do problema de classes, como pondera Oliveira (2003).

Essas questões nos colocam o desafio de compreender a modernização a partir de seu sentido histórico e espacial, o que exige examinar os processos e as ações. Se grande parte dos estudos sobre a modernidade limita-se aos níveis abstratos e ideológicos, aqueles da dita pós-modernidade também não deixam de apresentar a mesma característica, já que procuram analisar a cultura pela via das entidades e identidades. Caminhando em outra direção, a compreensão das ações dilui as identidades nos processos. Isto é, o esforço de compreender a dinâmica territorial de um lugar nos coloca diante de alguns obstáculos. E um deles é tentar criar identidades e/ou definir o indefinível, sobretudo tentar identificar algo que está em movimento. Como observa Bourdin (2001, p. 158), para evitar os obstáculos é preciso "deixar de lado as identidades (culturais, sociais...) e interessar-se pelos processos, quer dizer, pela maneira como se constrói a relação com um lugar. Para isso é preciso considerar a ação.”

É necessário preocupar com a modernização enquanto processo de expansão territorial da modernidade e/ou do modo de produção capitalista. Para tanto, o desafio que se impõe é aquele de considerar a modernização a partir da formação territorial (processos) que engloba a ação de atores sociais, das grandes empresas capitalistas, sobretudo do Estado por meio dos seus programas, projetos e políticas públicas. Este caminho pelos processos pode não só conduzir a uma compreensão mais dinâmica da complexa trama espacial induzida pela modernização como também chamar a atenção para o cuidado político e ideológico sem cair nas dualidades e sem representar a realidade espacial de maneira separada e fragmentada. 


\section{Considerações finais}

Todo período emblemático do ponto de vista das transformações que marcam o processo de modernização tem consequências sociais drásticas. Mas o preço que se paga por essas consequências é ocultado por meio dos discursos hegemônicos, processo do qual a ciência também não se isenta. Como processo contínuo de afirmação do "novo", mas também de sua negação/superação, a modernização coloca os pontos por onde ela se espacializa para além das fronteiras e dos limites político-administrativos. O território passa a ser configurado pelas redes e movido pelo cruzamento de variáveis internas sob hegemonia das variáveis externas. Na medida em que os elementos da mundialização penetram os lugares, os seus conteúdos são alterados e (re)funcionalizados.

Sendo hegemônico, o tempo veloz impõe ao território uma constante necessidade de inovação dos meios para a reprodução ampliada do capital. É o que vem ocorrendo, por exemplo, no território goiano. Estudos sobre esta Unidade da Federação, como exemplo de Arrais (2007), apontam para a necessidade de se considerar as bases técnicas e infraestruturais dos projetos de modernização e das políticas públicas, mas, sobretudo, a dimensão política desse processo. Mendonça (2001) e Chaveiro (2004) também demonstram que o entendimento da modernização é um caminho fundamental para a explicação das transformações territoriais de Goiás. Isso significa que é imprescindível compreender a modernização a partir de uma análise criteriosa da forma como ela se processa territorialmente a partir de dois sentidos: um ligado à ideologia e à política e outro ligado ao modelo que renova, constantemente, os meios de produção e a infraestrutura dos lugares. Assim, averiguar a atuação dos atores sociais, a sua inserção nas redes e, de modo concomitante, a nova dinâmica socioespacial são passos fundamentais para esse debate.

A reflexão aqui desenvolvida também ressalta que o conceito de modernização tem se apresentado bastante difundido nas instituições acadêmicas, no universo político bem como nos meios de informação. E essa difusão tem impedido uma fundamentação crítica no âmbito teórico e favorecido uma naturalização do fenômeno, colocando a expansão do modo de produção capitalista como algo necessário ao "progresso social" e considerando a pobreza, a forme e a segregação como resultado do atraso, ou como o avesso das sociedades modernizadas. Na verdade, como 
já dito anteriormente, a miséria não representa o reverso de um processo econômico, nem expressa atraso de um território, mas a contradição do tipo de modernização que vem sendo (re)produzida em países como o Brasil. E se ela está também nos lugares segregados, deve-se questionar a forma como ela os atinge. Fica evidente, então, que a superação das teorias dualistas como forma de interpretação da realidade é condição fundamental para uma construção teórica que possa abarcar a complexa dinâmica socioespacial da modernização. Assim dito, devemos debatê-la em sua raiz e discuti-la pela forma como é produzida, por quem e para quem. Isso significa que é preciso analisar os processos e as ações dos atores que a produzem, as dinâmicas socioespaciais daí resultantes, assim como averiguar, de maneira criteriosa, a formação territorial de cada lugar, região ou país por onde ela se expande bem como o modelo econômico e o sentido político que rege a sua expansão.

\section{Notas}

1 De acordo com Schwartzman (2004, p. 16), "uma pesquisa recente na Biblioteca do Congresso americano aponta a existência de 1.599 livros com a palavra "modernização". Uma breve pesquisa em qualquer biblioteca em Universidades do Brasil também nos apresentaria um número considerável. No catálogo on-line do banco de dados bibliográficos da Universidade de São Paulo (disponível no endereço eletrônico www-sbi.if.usp.br, acessado em 25 de agosto de 2010), por exemplo, foram encontrados 643 registros de obras (livros, teses, dissertações, artigos de periódicos etc.) com a palavra "modernização" no título. Em agosto de 2010 uma breve pesquisa no Google Acadêmico permitiu encontrar 76.900 resultados para a palavra "modernização".

2 É importante ressaltar que, apesar da proximidade dos termos modernização, modernidade e modernismo, há diferenças substanciais entre eles. Segundo Harvey (1993), modernidade é a racionalidade em evidência. Ela não apenas envolve uma ruptura com as condições históricas precedentes, "como é caracterizada por um interminável processo de rupturas e fragmentações internas inerentes" (Harvey, 1993, p. 21-22). Para este autor, modernismo enquadra a razão universal por meio dos códigos de valores universais. Podemos dizer, por conseguinte, que modernismo é uma corrente artística. Já a modernização é o capitalismo em ação por meio de suas classes hegemônicas; é o seu processo de expansão e/ou territorialização pelos lugares.

3 Harvey (1993) aponta a existência do pós-modernismo como uma forma de valorizar o pensamento que destaca o caos da vida moderna e a impossibilidade de lidar com ela pela via racional. Enquanto o modernismo dedica-se à busca do futuro pela via da razão, o pós-modernismo concentra-se nas circunstâncias produzidas pela fragmentação e pela instabilidade características da vida 
na atualidade. Ou seja, a flexibilidade da produção, a fragmentação e a instabilidade são elementos típicos do que Harvey chama de pós-modernidade. No entanto, como defende Berman (1982), a pós-modernidade representa um esforço empreendido pela mesma classe que criou as bases da modernidade. Se a pós-modernidade existe, ela está estocada no plano dos discursos e nos estudos que enfocam as identidades culturais e/ou as entidades sociais. Ou seja, trata-se de uma tentativa de desvio do que é, de fato, a modernidade. Assim, enquanto o capitalismo não for superado, ainda não teremos alcançado a dita pós-modernidade.

\section{Referências}

ANDRADE, M. C. Modernização e pobreza. São Paulo: Unesp, 1994.

ARRAIS, T. P. A. A região como arena política. Goiânia: Vieira, 2007.

BAUMAN, Z. Globalização: as consequências humanas. Rio de Janeiro: Jorge Zahar, 1999.

BERMAN, Marshall. Tudo que é sólido desmancha no ar: a aventura da modernidade. São Paulo: Companhia das Letras, 1982.

BLACK, C. E. Dinâmica da modernização. Rio de Janeiro: Apec Editora, 1971.

BOURDIN, A. A questão local. Tradução de Orlando dos Reis. Rio de Janeiro: DP\&A, 2001.

BRAUDEL, Fernand. Civilização material, economia e capitalismo: séculos XV-XVIII. O tempo do mundo. São Paulo: Martins Fontes, [1979]1996. v. 3.

CHAVEIRO, E. F. A urbanização do sertão goiano e a criação de Goiânia. In: GOMES, H. (Org.). O espaço goiano: abordagens geográficas. Goiânia: Associação dos Geógrafos Brasileiros, 2004.

DEBORD, G. A sociedade do espetáculo. Tradução de Estela dos Santos Abreu. Rio de Janeiro: Contraponto, 1997.

EISENSTADT, S. N. Modernização e mudança social. Belo Horizonte: Editora do Professor, 1968.

EISENSTADT, S. N. Modernização, protesto e mudança: modernização de sociedades tradicionais. Tradução de José Gurjão Neto. Rio de Janeiro: Jorge Zahar, 1969.

FURTADO, Celso. O mito do desenvolvimento econômico. 4. ed. Rio de Janeiro: Paz e Terra, 1974.

GERMANI, Gino. A sociologia da modernização. São Paulo: Mestre Jou, 1974.

GIDDENS, Anthony. Teoria da modernização e sua crítica. In: Sociologia: uma breve porém crítica introdução. Rio de Janeiro: Jorge Zahar, 1984. p. 111-119. GIDDENS, Anthony. As consequências da modernidade. São Paulo: Unesp, 1991. GOMES, Paulo César da Costa. Geografia e modernidade. Rio de Janeiro: Bertrand Brasil, 1996. 
GOMES, Paulo César da Costa. Um lugar para a Geografia: contra o simples, o banal e o doutrinário. In: MENDONÇA, F. et al. Espaço e tempo: complexidade e desafios do pensar e do fazer geográfico. Curitiba: DEMADAN, 2009.

GRAMSCI, A. A questão meridional. Rio de Janeiro: Paz e Terra, 1987.

GRAY, J. Al-Qaeda e o que significa ser moderno. Tradução de Maria B. de Medina. Rio de Janeiro: Record, 2004.

HABERMAS, Jürgen. O discurso filosófico da modernidade: doze lições. Tradução de Luiz Sérgio Repa e Rodnei Nascimento. São Paulo: Martins Fontes, 2002.

HARVEY, David. Condição pós-moderna. São Paulo: Loyola, 1993.

HOBSBAWM, E. A Revolução Francesa. São Paulo: Paz e Terra, 1996.

HOUAISS, Antônio; VILLAR, Mauro de Salle. Dicionário Houaiss da língua portuguesa. Rio de Janeiro: Objetiva, 2001.

IANNI, O. Enigmas da modernidade - Mundo. Rio de Janeiro: Civilização Brasileira, 2000

KURZ, Robert. O colapso da modernização. Rio de Janeiro: Paz e Terra, 1992. p. 185-207.

LEFEBVRE, Henri. La production de l'espace. 4. ed. Paris: Anthropos, 2000.

MARX, Karl; ENGELS, Friedrich. O manifesto comunista. 10. ed. Tradução de Maria Lucia Cumo. Rio de Janeiro: Paz e Terra, 1998. (Coleção Leitura).

MENDONÇA, M. R. A urdidura espacial do capital e do trabalho no Cerrado do Sudeste Goiano. 2001. Tese (Doutorado em Geografia) - Universidade Estadual Paulista Júlio de Mesquita Filho, Unesp. Presidente Prudente, 2001.

MÉSZÁROS, I. Marx: a teoria da alienação. Rio de Janeiro: Zahar, 1979.

NIETZSCHE, F. Além do bem e do mal. Tradução de Antônio Carlos Braga. 2. ed. São Paulo: Escala, 2007.

OLIVEIRA, F. de. Crítica à razão dualista. O ornitorrinco. São Paulo: Boitempo, 2003.

ORTIZ, Renato. Mundialização e cultura. São Paulo: Brasiliense, 2003.

REIS, João Paulo. Modernização do capitalismo brasileiro. São Paulo: José Olympio, 1988.

RIBEIRO, Ana Clara Torres. Metrópole e fragmentação: novos rumos na análise da modernização. In: SANTOS, M; SOUZA, M. A. A. de. SOUZA; SILVEIRA, M. L. (Orgs.). Território: globalização e fragmentação. 5. ed. São Paulo: Hucitec/ ANPUR, 2002.

RIBEIRO, Guilherme. Modernidade e espaço, pós-modernidade e mundo: a crise da geografia em tempos de globalização. Diez años de cambios en el mundo, en la Geografía y en las Ciencias Sociales, 1999-2008. Actas del X Coloquio Internacional de Geocrítica, Universidad de Barcelona, 26-30 de mayo de 2008. Disponível em: <http://www.ub.es/geocrit/-xcol/154.htm>.

SANTOS, M. O espaço dividido: os dois circuitos da economia urbana dos países subdesenvolvidos. Rio de Janeiro: Francisco Alves, 1979. 
SANTOS, M. Metamorfoses do espaço habitado. São Paulo: Hucitec, 1988.

SANTOS, M. Técnica, espaço, tempo: globalização e meio técnico-científico-informacional. São Paulo: Hucitec, 1994.

SCHWARTZMAN, S. Pobreza, exclusão social e modernidade: uma introdução ao mundo contemporâneo. São Paulo: Augurium, 2004.

VIANA, N. Modernidade e pós-modernidade. Revista Enfrentamentos, Goiânia, ano 4, n. 6, jan./jun. 2009.

VIRILIO, Paul. O espaço crítico. São Paulo: Editora 34, 1993.

Denis Castilho - Professor assistente do Instituto de Estudos Sócioambientais da Universidade Federal de Goiás e doutorando em geografia pela mesma universidade.

Recebido para publicação em agosto de 2010 Aceito para publicação em novembro de 2010 